\title{
The Establishment of the Green Tax Policy in China - To Accelerate the Construction of Circular Economy Experimental Zone in Qaidam Basin of Qinghai Province as an Example
}

\author{
Afan Sun $^{1}$ \\ ${ }^{1}$ School of Economics, Northwest University for Nationlities, Lanzhou, China \\ Correspondence: Afan Sun, School of Economics, Northwest University for Nationlities, No.589 Gannan Street, \\ Lanzhou, Gansu, China. Tel: 86-931-881-4376. E-mail: sunaf02@126.com
}

Received: December 3, 2012 Accepted: January 23, 2013 Online Published: February 28, 2013

doi:10.5539/ass.v9n3p148 URL: http://dx.doi.org/10.5539/ass.v9n3p148

The article supported by the Fundamental Research Funds for the Central Universities (zyz2011015).

\begin{abstract}
"The overall plan on the test zone of circular economy in Qaidam area of Qinghai province" provided approval by the State Council on March 15, 2010, which was the second regional recycling economy program after Gansu Province. As the largest circular economy area, its success would have far-reaching effects. As the basic means of government regulation, the taxation would play very important role in the development of recycling economy. The establishment and improvement of green tax policy would be the effective means to impel the construction of circular economy test zone in Qaidam area.
\end{abstract}

Keywords: Qaidam area, circular economy, green tax

\section{Introduction}

The circular economy is one economic model which is conducive to conserve resources and protection environment. Within the large system of human, resources and technology, the economic growth model transforms from extensive to intensive, and the product model changes from "resources--products--waste" which rely on resources consumption to "resources--products--reproduction resources" which rely on resources recycling. In this economic model, according to the substance loop of natural ecosystem and the flows of energy, resource efficient recycling is the core, following the principle of "reduction quantitative, reuse and resources ".

To make circular economy in China as soon as possible to be comprehensive, in-depth implementation, and to play an active role in its economic construction, the government must be matched with the relevant policies and instruments. Tax as the basic means of government regulation, most can play the role to move mountains with few resources. Therefore, the establishment of a green tax system is especially important.

There exists a sizable literature on the acceptance of green tax. The relationship between economy and green tax has been widely analyzed in the last decade. Many studies have shown that conventional results from tax theory are not carried over to the models of environmental protection in China. In recent years, with the development of economy, the analysis of green taxation has been extended to the problem of environmental regulations.

Yan Chen (2005) thought along with the environmental problem getting obvious in China, green taxation, as one of the principal means of governments' macro-regulation, is also very important for China's environmental protection. Aizhu Zhang (2006) and Jingqing Hu(2006) and Yun Ding (2007) expressed the view that the Green tax system is one of the effective economic means with theoretical background and empirical confirmation. The required innovation in a green tax system should be carried out in China by using the successful overseas experience for reference, and the tax items and tax rates of the resource tax and the like in the existing system should be adjusted, and the tax-related regulations concerning the environmental protection should be updated so as to formulate the normal green tax system.

Yajun $\mathrm{Wu}$ (2008) opined that the transitional development of China's economy is facing the great challenge of resource and environmental constraints and the changing economic growth pattern. Green taxation possesses the efficiency mechanism of controlling pollution and facilitating the use of natural resources efficiently. Yansong 
Zhu (2009) opined that against the increasingly serious environmental pollution problems and waste of resources and energy security issues, government needs to use economic instruments of tax to address. China's government should bring forward timely to reform the resource tax, to research the imposition of environmental taxes, and to construct a green tax system in China. It is also suggested (Bai, 2009) that construction of a set of green taxation is a path. China shall take for future tax reform, and come up with a fundamental idea to start to levy a new tax the environmental tax.

Liping Liu (2006) and Meng Li \& Haibo Zhang (2008) and Jing Huang \& Mingrui Xu (2009) and Xiaolu Gao (2010) and Kuifang Zhan (2011) suggested that establishing green tax systems is an important step in achieving sustainable development and constructing a harmonious society in China, and should draw on the experiences of developed countries to establish green tax system with Chinese characteristics including the complete set system and implementation of a green tax.

\section{The Important Meaning of the Construction of Circular Economy Experimental Zone in Qaidam Area of Qinghai Province}

Qinghai province is one of the more vulnerable areas of ecological environment in China, but the rich mineral resources, has great potential for development. Now, Qinghai province faces great pressure on environmental protection, which results from promoting economic development depending on extraction and preliminary processing of mineral resources for many years (see Figure 1,2). The construction of circular economy experimental zone in Qaidam area will achieve far-reaching significance to promote the adjustment of economic structure and fulfill sustainable development in Qinghai province.

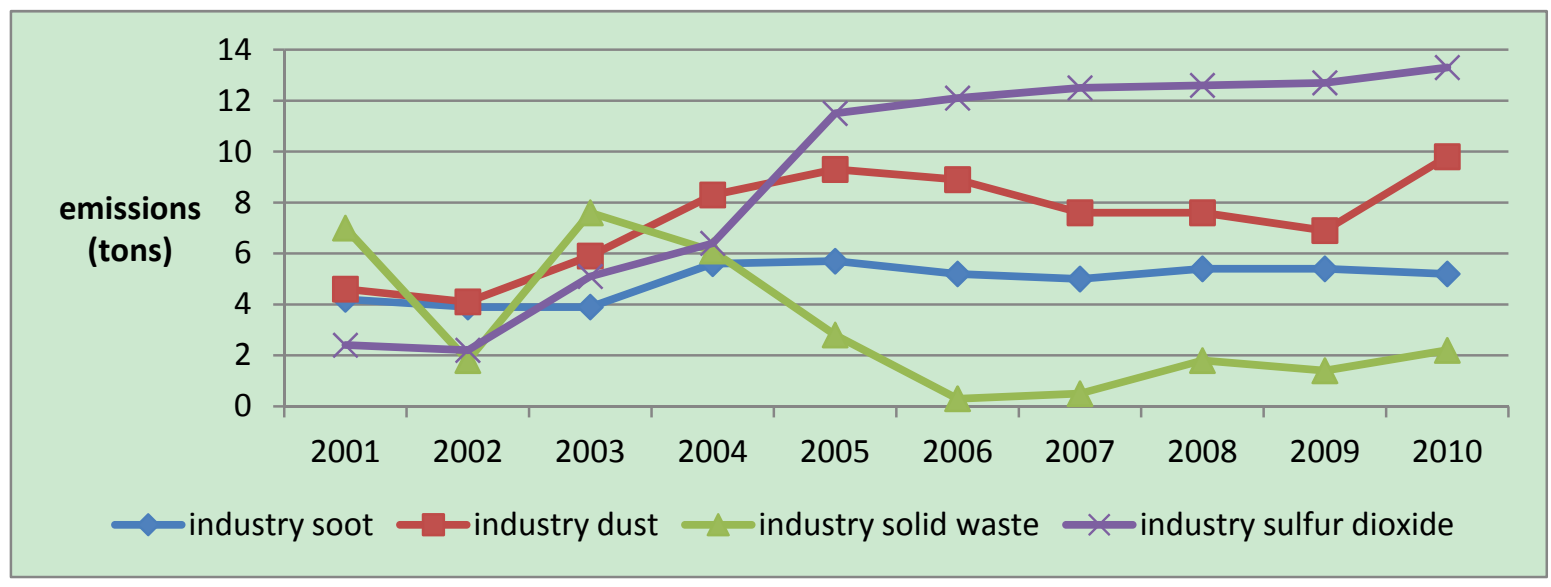

Figure 1. The major industrial pollutant emissions from 2001 to 2009 of Qinghai Province's principal

Data come from the Chinese economy database.

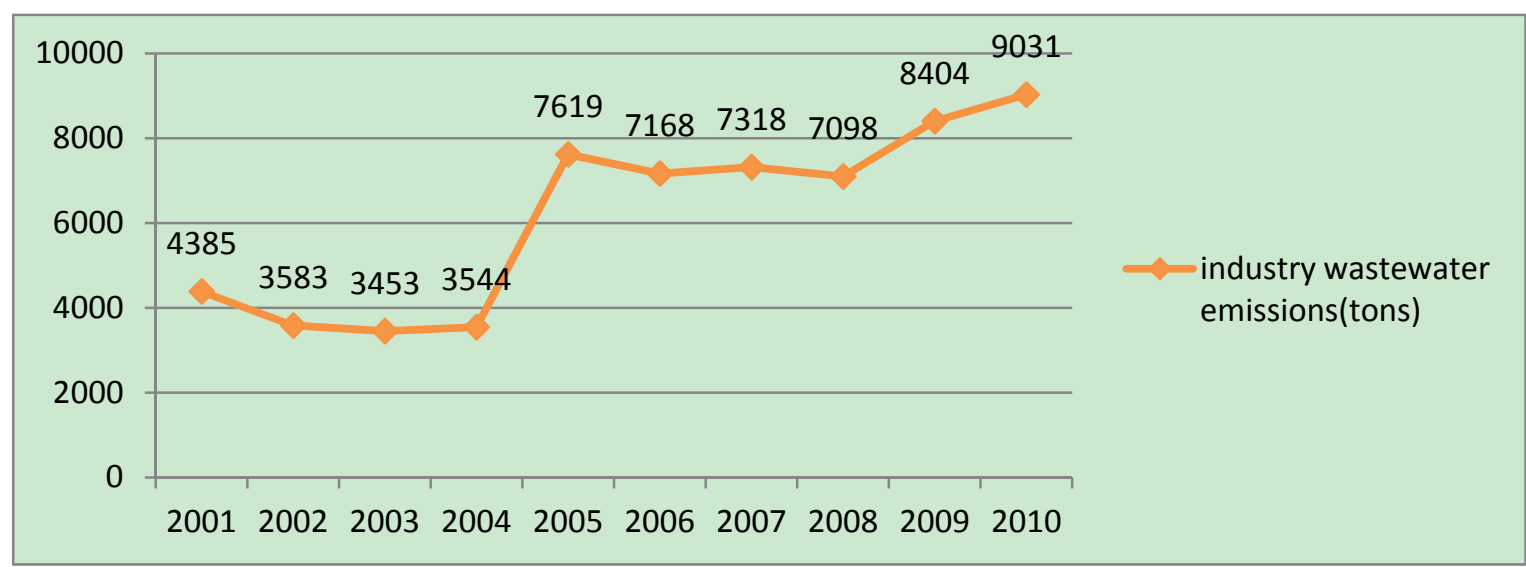

Figure 2. The industrial wastewater emissions of Qinghai Province from 2001 to 2009

The data come from the Chinese economy database. 


\subsection{Attain the Double Goals of Resource Development and Environmental Protection in Qaidam Area}

The Qaidam region is the largest domestic recycling economy Park in China. It also plays such an important role in developing resource and promoting industrializing in Qinghai province and the West China Area. In Qaidam region, it is richly endowed with mineral resources, providing a premise for developing circular economy. The potential economic value is more than 16 trillion, and their category is completely, marginal grade is high, and the industrial structure is widely association. However, the ecosystem of the area is very fragile, and the problem of desertification, soil salinization and waste pollution during long-term resource development is serious. Therefore, developing the recycling economy oriented "reduction, zero emission" can effectively shun the unpromising way of "pollution first, treatment afterwards" in economic growth, and can contribute to the new development path that resource exploitation and environmental protection synchronize simultaneously in the Qaidam area.

\subsection{Conductive to Adjust the Industrial Structure and Promote Fundamental Shift in the Economic System and Mode of Economic Growth of Qinghai Province}

Under the economic growth mode which places emphasis on resource exploitment, the secondary industry, especially the heavy industry plays an important role in Qinghai province's industrial structure. The enterprise's scale is small, the production processes is behind schedule, by-products and waste have not been exploited, all these not only form a large number of resources waste, but also cause the deterioration of ecological environment Such objective conditions with lack of industrialization and easy to exploit resources will make the Qinghai Province's economic growth dominated by resource industries for quite a long time. If we do not fundamental change the huge resource consumption-led growth model will inevitably lead to heavy pressure on ecological environment.

To resolve the dilemma proposition, we will have to adapt the existing industrial structures under the guidance of market mechanism, nurture and develop strategic emerging industry characterized by recycling economy, increase the resource utilization, and turn resource advantages into economic advantages. The construction of circular economy experimental zone in Qaidam area is typical practice for this purpose.

\subsection{Optimize the Industrial Distribution in Qinghai Province}

At present, over $80 \%$ industrial enterprises in Qinghai province are small businesses, which make little contribution to economy. In construction of the circular economy experimental zone of Qaidam area, the practice based on comprehensive utilization of resources in Salt Lake, devoted major efforts to develop salt chemical, coal chemical, petroleum chemical industry, and non-ferrous metallurgical industry, is conducive to play industrial agglomeration effect, form the resource recycling chain, improve production efficiency and reduce environmental pollution.

For example, the project which has been already built, including the millions tons of potash project in Qinghai salt lake, the 900,000 tons of soda ash project of Qinghai Alkali industry, 1 million tons of coal chemical engineering of Ulan, and the project under construction including the comprehensive utilization of millions of tons of potash projects phase I and II, will help the Qaidam basin become the typical demonstration area of advanced technology, clean production, circular development, and comprehensive utilization of resources.

\section{The Green Tax System Orientation of Promoting the Construction of Qaidam Circular Economy Experimental Zone}

The green tax is one system associated with resource utilization and environmental protection, the purpose of which is to rationally develop and utilize the resource, promote the production and consumption of green. The end of the last century, a number of countries in Europe and United States make taxes contribute significantly to improve the environment through introducing the environmental taxes and adopting the preferential tax policy. Under the trend of green tax system, to build the same system is imperative in China.

\subsection{Improve the Tax System}

\subsubsection{Accelerate the Pace of Resource Tax's Reformation}

Scope of current resource tax in China is small, and rate is low. It cannot fully reflect the scarcity of resources and external costs of exploitation and use. On June 2010, Xinjiang province has proposed the reform of resource tax on crude oil and natural gas, ad valorem and the rate was $5 \%$. The reforms got positive assessment. To give full play to the regulatory function of the resource tax and promote the construction of the Qaidam circular economy pilot area, we should further establish and improve tax reforms on the progress made at Xinjiang, oriented by constraining the excessive use of energy resources and strengthen environmental protection. On the 
one hand, the count should consider broadening the resource tax base, extended to other resources such as land, forest, and water. On the other hand, the count should consider reforming the mode of measurement based on the scarcity of resources and the connection of environment from single specific duties to ad valorem duties or the combination of both, and appropriate increase in the tax burden and tax rates. It is important to adjust the economic structure and accelerate reform of the price-setting mechanism of resource products.

\subsubsection{Continue to Improve the Excise Tax}

The excise tax also is one of the important tools to protect the environment. In 2006, China implemented an adjustment on a large scale since 1994. According to the census data from 2005 to 2008, the State Taxation Administration believes since the implementation of the exercise tax reform, it has reached the desired purposes of organizing the financial income, guiding and mediating consumption, conserving resources, and promoting environmental protection.

However, from the level of green tax system, there is room for further adjustment. For one thing, the range of taxation still exist absence, especially as non-degradable plastic products, high quality building decoration materials, batteries, and other items of harm to the environment. All these should be included in consumption according to the relationship with environmental damage. For another, in order to strengthen consumer restriction, the differential tax rates can be set based on the degree of products' environmental friendliness, and differentials can be expended appropriately.

\subsubsection{Build the Environmental Tax}

The social production and consumption behavior must be reasonable use from a conservation point of view, determined by non-renewable and scarcity of resource. While the exploitation of resource is harmful to environment. All these require the environmental tax should be designed to preserve resources and environment. The environmental tax is based on the harm to society caused by the discharge of pollutants to improve the environment, increase the output and promote employment, designed by adding pollution cost to the product price to make up for the disparity between social costs and private costs through taxation.

At present, the developed countries are levying environment tax such as sulphur dioxide tax, water pollution tax, solid waste tax, and garbage tax. Achievements were made by them. Environmental pollution tax in the current tax system is just a collection of excessive discharge according to state provisions and the ecological environment recovery payments. However, the pollution discharge fee standards are too low ,and enterprises and institutions would pay the fee for the excessive discharge of pollutants rather than taking measures to eliminate and control the pollution, which could not achieve the purpose of protecting the environment.

Therefore, the Chinese government should make scientific decisions to levy environmental tax by drawing on the experience of other countries. In the short run, according to environmental improvement and economic growth with the government's focus of development, as long as unable to prove that the environmental tax reform will cause environmental degradation can be implemented, supporting other policy tools to supply the demand of economic growth and environmental protection. Over the long term, environmental tax must be reformed and be imposed, which has great significance of improving the environment and promoting the economic development.

\subsection{Improve Preferential Tax Policies}

Oates, Rosen and other economists suggested that the local government's policy trial can be pushed around the political obstacles, and can generate innovative policies and proposals by using the acquaintance with local residents and resources, promoting technological progress of public policy through intergovernmental competition.

In the construction of Qaidam Basin's circular economy pilot zones, the local government can also bring forth a number of policy innovations within the scope of authority.

\subsubsection{Improve Preferential Policies on the Corporation Income Tax and Value Added Tax (VAT)}

As two major types of taxes of many production enterprises mainly undertake, the corporation income tax and value added tax directly affect the initiative of enterprises. But the enterprise income tax only is directed the income generated for the projects of environmental protection, energy or water saving, satisfying the related requirements implementing preferential policy such as from one to three years shall be exempted from the revenue and halve from four to six years since the first profit-making year. As regards the amount of an enterprise's investment in purchasing special equipment for protecting environment, the tax amount may be deducted at $10 \%$, and can be carried forward for set-off in the following 5 tax years. The income of compliance 
products produced by specified resources as its main raw material can be levied at the reduced tax rate of $90 \%$.

In VAT, the sales revenue of rejuvenated water, special materials of construction, and sewage dispose is exempted from VAT. A drawback can be made to the sales revenue of high purity $\mathrm{CO}_{2}$ products derived from industrial exhaust, and power and heat derived from refuse. The by-products by desulfurization of flues to the smoke and high-sulfur gas produced by plants, power and heat produced by coal gangue and coal mud for use as fuel can be drawn back $50 \%$. The sales income self-produced biodiesel by comprehensively utilizing refund after collection.

In addition to implementing the above policies, the Qaidam Basin may also introduce new measures in the construction of circular economy pilot zones: allowing to accelerate the depreciation of environmental equipment and to increase the usage time in enterprise income tax; granted more substantial deductibles before tax to the research and development funding on environmental protection project. In VAT, law tax rate should be implemented to the sales of pollution-reducing equipment on dedust and sewage disposal; the promotions time of VAT rebate should be prolonged for the taxpayers selling renewable resources. In addition, it should restrict the enterprise to sell old production facilities that will not meet the requirements of environmental protection and require them to bear certain recovery cost, repeal provisions to law tax rates of toxic pesticides, plastic sheeting, etc.

3.2.2 Optimize and Integrate the Existing Taxes to Create a Favorable Environment for the Implementation of Environmental Taxes

At the current stage, in addition to levy resource tax, the Chinese government also collect the resources compensation fees, royalties, and petroleum windfall profits tax. The mining companies also pay the administrative charges such as fees for mineral prospecting and mining rights, mining registration fees, and survey registration fees. The nature of taxes tends to convergence, function is approximation, and management is irregularities. The external resources tax regulations mainly include the royalty of owner's equity, the resource rent tax of excess profits and mineral rights premium paid by people who own mining rights according to law when nation transfer it.

In the construction of green taxation system, it should place the industrial chain optimization and adjustment of the interest's distribution as the core, optimized the integration of existing taxes from safeguarding the proceeding rights of possession, use, benefits, disposition, to promote the rational exploitation of resources and the effective use, and guarantee the income and essential interests between the central and local governments, but also conducive to the sound development of enterprises.

3.2.3 Reduce the Tax Which Belongs to the Fixed Income Portion of the Central Budget Under the Tax Assignment System

Currently, VAT and enterprise income tax are taxes shared by central and local government. Among them, the central government respectively gets the tax revenue's $75 \%$ and $60 \%$. However, after taking into account the import linkage VAT, the central government in the share of VAT revenue is always higher than $75 \%$, and presents the trend of rising. If taking into account the income tax paid by the Railway Ministry, head office of banks and offshore oil enterprises, the tax revenue owned by central government is higher than $60 \%$.

So, the preferential policies might be considered to proper reduce the proportion of central government and directionally leave it to the local governments earmarking for its specified purpose only of environmental protection. At the same time, the appropriate amount of funding should be allocated to the local from the annual State budget to advance the construction and development of circular economy as compensation for environmental protection and resource output on an annual allocation.

\section{Conclusion}

Since Pigou's work, environmental tax has been considered as one of the most efficient environmental policy tools. Environmental tax reforms have become increasingly popular in recent years. One reason is increasing concern about the quality of the natural environment; environmental taxes are generally an efficient instrument for protecting the environment. A second reason involves the revenues from environmental taxes. These revenues can be uses to cut other, distortionary taxes.

The Chinese government also become pay more attention to protect the environment. This paper contributes to the existing theoretical literature in three ways. First, China's current tax structure is the central and local revenue-sharing. Therefore, the implementation of green tax policy depends on the joint efforts of central and local government. Qinghai province, as a province of ecological source in China, the implementation of the system has a unique advantage. 
Second, the effects of green tax has been studies and taken in many developed countries. The effectiveness of green tax fundamentally depends on the level of other taxes and policies including resources tax, excises tax, VAT, and so on. By introducing environmental taxes, we evaluate the effectiveness of green tax in a broader context.

Third, having submitted the suggestions of establishing the green tax policy, we think there are more benefits in green tax reform. The government may reap a 'double dividened'-not only a cleaner environment but also a less distortionary tax system. If the double dividend hypothesis holds, an environmental tax reform is a so-called 'no-regret' option; even if the environmental benefits are in doubt, an environmental tax reform may be desirable. The Chinese government would get more revenue from environmental tax. The result implies the government needs to set environmental standards higher in order to keep the existing level of public spending under a green tax reform.

In short, to build a resource-conserving and environment-friendly society, developing the green economy, circular economy and low carbon economy, the green tax system is one of the important economic means that the government can be selectable. With Qaidam circular economy pilot area's construction, Qinghai province should make use of the opportunity to promote the establishment and improvement of green tax system, to assist the central government promoting institutional innovation.

\section{References}

Bai, Y. F. (2009). Some Ideas on Establishing a Green Tax System in China. International Taxation in China, (7), 28-31.

Bai, Y. F., \& Wu, Z. F. (2010). VAT Central and Local Governments Share Proportion. Finance \& Trade Economics, (3), 39-46.

Bovenberg, A. L. (1999). Green Tax Reforms and the Double Dividend: an Updated Reader's Guide. International Tax and Public Finance, 6, 421-443. http://dx.doi.org/10.1023/A:1008715920337

Chen, Y. (2005). Several Imagination on Establishing and Improving the Green Taxation System of our country. Journal of Qingdao University of Science and Technology (Social Sciences), 21(4), 49-52.

Ding, Y. (2007). Some Thoughts on Building a Green Tax System. Taxation Research Journal, (266), 17-19.

Dong, Z. P. (2009). Review on the Theory of Fiscal Decentralization. Contemporary Economy \& Management, $31(9), 1-6$.

Gao, X. L. (2010). The Circular Economy Perspective Green Tax System. Research on Financial and Economic Issues, (314), 94-98.

Hu, J. Q. (2006). An Exploration of Green Taxation. Taxation Research Journal, (254), 38-40.

Huang, J., \& Xu, M. R. (2009). The Idea of Building the China's Green Tax System. Taxation Research, (290), 32-34.

Li, M., \& Zhang, H. B. (2008). Foreign Experiences on Establishing "Green Tax" Systems in China. International Taxation in China, (11), 22-25.

Liu, L. P. (2006). The Green Foreign Tax System. Scientific Decision-making, (7), 47-48.

Sugeta, H., \& Matsumoto, S. (2005). Green Tax Reform in an Oligopolistic Industry. Environmental \& Resource Economics, 31, 253-274. http://dx.doi.org/10.1007/s10640-004-8249-z

Wu, Y. J. (2008). Transition, Green Taxation and Sustainable Development. Journal of China University of Geosciences (Social Sciences Edition), 8(1), 5-14.

Zhan, K. F. (2011, January). The Revelation of the Green Tax System Abroad for the Building of China's Green Tax System. Journal of Weifang University, 11(1), 106-108.

Zhang, A. Z. (2006). Construction of a Green Tax System in China. Taxation Research, (254), 44-46.

Zhu, Y. S. (2009). Orientation of the Resources and the Environment Tax under the Condition of the Green Tax System. Reform, (187), 63-67. 